\title{
PROGRAM INTERNET OF THING (IoT) E-KB BIDAN DELIMA
}

\section{MENINGKATKAN KINERJA PELAYANAN BIDAN}

\author{
Dwi Setia Mujiono', Imam Bukhari ${ }^{2}$, Umriaty $^{3}$ \\ Email: 1dwichoshy@gmail.com, ${ }^{2}$ bukhari.imam@yahoo.co.id, ${ }^{3}$ umri.midwife@gmail.com \\ Politeknik Harapan Bersama Tegal
}

\begin{abstract}
Abstrak
Penelitian yang dilakukan tujuan jangka panjangnya adalah diperolehnya sebuah model terbaik yang dapat diimplementasikan dan dikembangkan kedalam sebuah aplikasi komputer dengan menggunakan bahasa pemrograman tertentu untuk dapat digunakan sebagai alat semua bidan pengganti kartu KB yang hardcopy ke bentuk elektronik. Metode penelitian yang digunakan dalam penelitian adalah metode Recearch And Development ( $\mathrm{R} \& \mathrm{D})$. Metode penelitian ini digunakan untuk menghasilkan produk tertentu dan mengkaji keefektifan produk tersebut. Dataset pengambilan datanya diambil berdasarkan wawancara dan pengamatan BPS, Puskesmas dan ke masyarakat langsung di daerah Tirto kabupaten Pekalongan. Penelitian ini mengguna $P H P$ dengan menggunakan database MySQL. Banyak manfaat dan keuntungan dalam penggunaan barcode scanner diantarnya yaitu proses input data lebih cepat karena barcode scanner dapat membaca atau merekam data lebih cepat dibandingkan dengan melakukan proses input data secara manual, proses input data lebih tepat karena teknologi barcode mempunyai ketepatan yang tinggi dalam pencarian data dan penelusuran informasi data lebih akurat karena teknologi barcode mempunyai akurasi dan ketelitian yang sangat tinggi.Adapun hasil akhir dari penelitian ini adalah sebuah sistem aplikasi E-KB yang bersifat otomatisasi dengan memanfaatkan barcode scanner sehingga mempermudah segala transaksi padaE-KB. Penelitian yang akan dilakukan ini untuk menghasilkan sebuah alat yang digunakan untuk mengganti kartu $\mathrm{KB}$ yang biasa digunakan bidan praktek swasta.
\end{abstract}

Kata kunci : Bidan, Kartu KB, Internet Of Thing (IoT).

\section{Pendahuluan}

Salah satu upaya yang dilakukan pemerintah untuk mengurangi jumlah penduduk di Indonesia yaitu dengan dicanangkannya Keluarga Berencana (KB). Keluarga Berencana diidealkan sebuah keluarga hanya terdiri dari orang tua dan dua orang anak. Dengan hanya memiliki dua anak saja, diharapkan beban keluarga berkurang, sehingga dapat meningkatkan kesejahteraan keluarga Indonesia. Orang tua dapat menyekolahkan anak-anaknya, dapat memenuhi semua kebutuhan anak-anak dan ekonomi keluarga menjadi lebih sejahtera.

Keluarga Berencana merupakan upaya pemerintah mewujudkan kebahagiaan dan kesejahteraan keluarga. Tujuan utama dari Keluarga Berencana adalah untuk lebih meningkatkan kesejahteraan ibu dan anak. Dengan mengatur kelahiran, Isteri banyak mendapat kesempatan untuk memperhatikan dan mendidik anak-anak disamping memiliki waktu yang cukup untuk melakukan tugastugas sebagai ibu rumah tangga. Di pihak lain suami tidak perlu direpotkan oleh tuntutan biaya hidup serta biaya pendidikan anak. Lebih dari itu anak-anak akan mendapatkan perhatian yang cukup dari orang tua yang kelak dapat memberikan dampak positif bagi tumbuh kembang kepribadian anak, sehingga menjadi manusia yang sehat secara fisik, mental dan sosial sesuai dengan apa yang dikehendaki dan diperintah oleh agama menjadi anak yang sholeh.

Kartu elektronik mulai banyak digunakan, dengan berbagai jenis kartu elektronik yang sudah ada, seperti Magnetic stripe card, chip card dan yang terbaru adalah contactless card, kartu ini menggunakan gelombang radio, cara kerja dari kartu ini cukup dengan mendekatkannya dengan perangkat pembacanya (RFID reader), kartu ini juga sering disebut sebagai RFID, salah satu penggunaan kartu ini adalah $\mathrm{E}-$ KTP.Perkembangan RFID merupakan penerus atau pengganti dari teknologi barcode, dengan keunggulan RFID yaitu dari cara pembacaannya tanpa melakukan kontak secara langsung sehingga proses pembacaan lebih cepat. Implementasi RFID ini efektif digunakan untuk instansi atau perusahaan yang memerlukan akurasi data dan kecepatan dalam identifikasi data. 
Internet of Things (IoT) adalah sebuah solusi terintegrasi yang merasakan dan mengumpulkan data dari berbagai perangkat, analisis data dan dilakukan tindakan untuk mencapai tujuan bisnis tertentu (Reeves, 2016). Pengumpulan data dari berbagai perangkat dengan menggunakan komunikasi kabel dan nirkabel melalui internet dan dianalisa dengan berbagai kategori untuk dapat digunakan sebagai data analitik untuk kebutuhan bisnis tertentu dan spesifik.

IoT merupakan salah satu teknologi yang berkembang berbasis bisnis (businessdriven) dan dorongan perusahaan untuk melakukan efisiensi \& penghematan biaya, customer experience dan peningkatan keuntungan perusahaan. Dengan adanya IoT, stakeholder logistik berharap adanya transparansi \& kontrol terintegrasi (right products, at the right time, place, quantity, condition and the right cost) dalam optimalisasi dan efisiensi kegiatan logistik (Macaulay dkk., 2015).

Berdasarkan uraian di atas akan dibuat sebuah alat Program Internet of Thing (IoT) e- KB yang dapat digunakan di puskesmas dan bidan praktek swasta. alat Program Internet of Thing (IoT) e- KB ini dibuat agar dapat membantu bidan praktek swasta dan membantu masyarakat yang menggunakan alat $\mathrm{KB}$ suntik 1 bulan maupun 3 bulan. Algoritma perancangan alat Program Internet of Thing (IoT) e- KB ini, selanjutnya dianalisa untuk mengetahui keberhasilan alat ini.

\section{Metode Penelitian}

Penelitian ini bertujuan untuk mengembangkan produk berupa aplikasi komputer untuk mempermudah kerja Bidan Praktek swasta di daerah tirto Pekalongan memantau pasiennya. Penelitian ini termasuk dalam penelitian Recearch And Development (R \& D). Metode penelitian ini digunakan untuk menghasilkan produk tertentu dan mengkaji keefektifan produk tersebut.

\section{Hasil dan Pembahasan}

Aplikasi E-KB mengunakan IoT yaitu suatu perangkat lunak komputer yang dikembangkan untuk membantu Bidan Praktek swasta menjalankan praktek berkaitan dengan pelayanan KB. Dengan kata lain E-KB mengunakan IoT merupakan aplikasi komputer berkaitan E-KB yang dikembangkan oleh penulis sendiri. Tujuan utama dari pengembangan E-KB mengunakan IoT adalah mempermudah kerja bidan swasta dalam menjalankan pelayanan $\mathrm{Kb}$ dan membuat pasien $\mathrm{KB}$ tidak terlambat kembali untuk suntik KB..

E-KB mengunakan IoT dikembangkan menggunkan aplikasi PHP dan mysql yang menghubungkan secara offline. aplikasi ini memungkinkan di mempercepat kerja bidan praktek swasta. Berikut adalah tampilan awal E-KB mengunakan IoT yang sudah di buat.

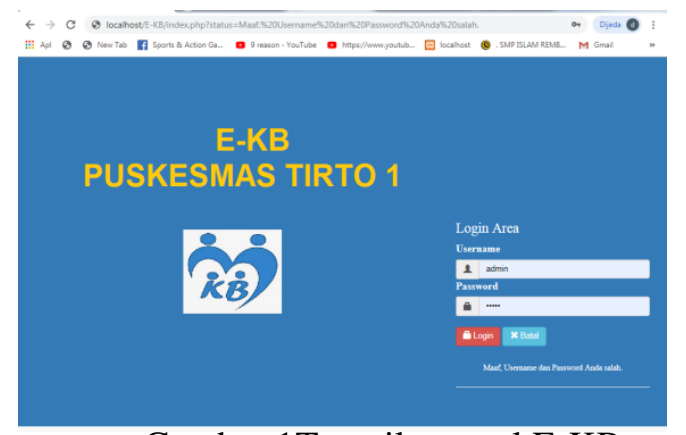

Gambar 1Tampilan awal E-KB alur proses sistem yang terjadi didalam aplikasi E-KB.

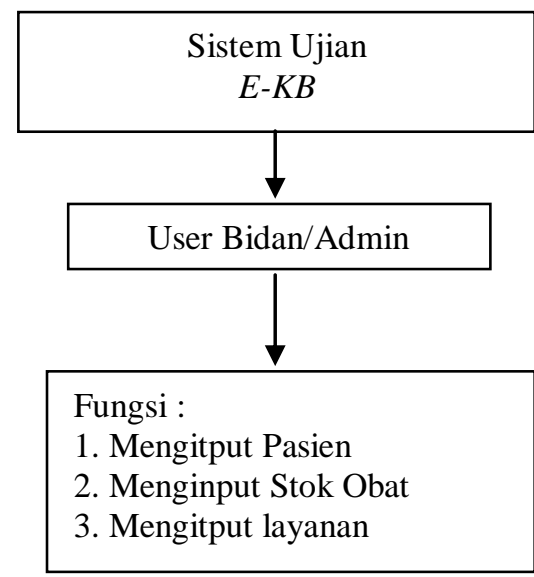

Berikut adalah gambar di aplikasi E-KB

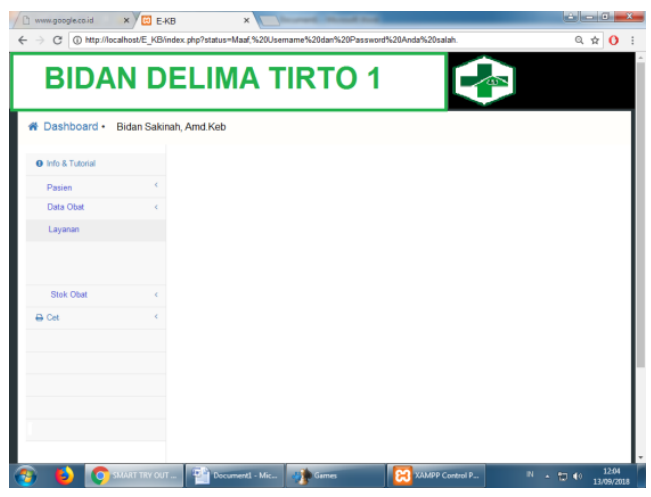

Gambar 2 Aplikasi E-KB 
Hasil penelitian yang pertama adalah tersusunnya aplikasi E-KB mengunakan IoT yang akan digunakan di praktek bidan swasta. Pengembangan aplikasi E-KB mengunakan IoT di awali dengan pengumpulan informasi kebutuhan bidan praktek swasta. Data dari tahap awal pengumpulan informasi menjadi pedoman bagi peneliti untuk melakukan analisis kebutuhan dalam kegiatan perancangan E$\mathrm{KB}$ mengunakan IoT dan untuk menyusun konsep E-KB mengunakan IoT untuk mempermudah kerja bidan praktek swasta. Informasi tersebut yakni tentang bagaimana setiap bidan swasta menggunakan kartu KB dalam menjalankan praktek pelayanan KB.

\section{Kesimpulan}

Aplikasi E-KB mengunakan IoT digunakan untuk mempermudah dan memantau pasien yang datang untuk KB di BPS, Mengurangi keterlambatan pasien saat diharuskan kembali berobat, Menghindari kehamilan karena keteledoran pasien tidak datang tepat waktu.

\section{Daftar Pustaka}

[1]. Aditya, A.L. jago PHP \& MySQL, dunia komputer, Jakarta, 2011.

[2]. Anhar, Panduan Menguasai PHP dan MySQL, Jakarta, 2010

[3]. Borg, Walter R., Gall M. D \& Gall, Joyce P. 2003. Educational Research: an Introduction 7th Ed. NewYork: Pearson Education .Inc

[4]. Eniyati, Sri. "PENGGUNAAN METODE CMS UNTUK SISTEMINFORMASIKIA DAN KB" . proseding seminar nasional multi disiplin ilmu. stie kubank semarang. 2016.

[5]. Gustari, Robi. "Perancangan Sistem Pembaca Kartu Mahasiswa Berbasis Radio Frequency

[6]. Identification" . Jurnal algoritma. sekolah tinggi teknologi garut. 2015

[7]. Kurniawan, R, PHP \& MySQL untuk Orang Awam, Maxikom, Palembang, 2010.

[8]. Macaulay, J., Buckalew, L., and Chung, G. 2015. Internet of Things in Logistics, A collaborative report by DHL and Cisco on implications and usecase for the logistics industry, DHL Trend Research \& Cisco Consulting Services.

[9]. Ramdhani dkk "Telematic Policy Analysis in Developing Countries:A Case Study in Garut Districtindonesia," Journal of Applied Sciences Research, vol. 2, no. 1, pp. 58-66, 20067.

[10].Rosa D, dkk, Pemrograman Basis Data Berbasis Web Menggunakan PHP dan MySQL, Bangkalan, 2010. 